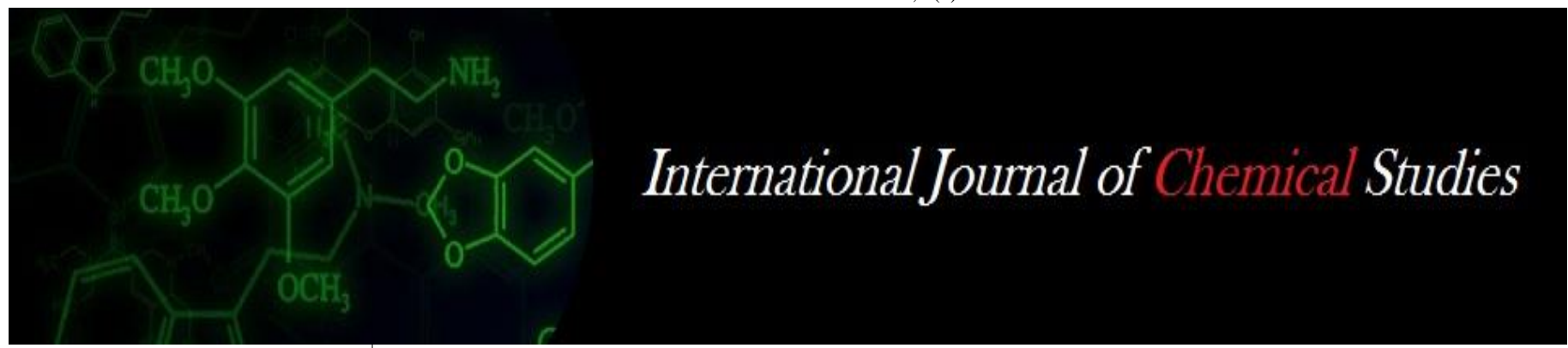

P-ISSN: 2349-8528

E-ISSN: 2321-4902

www.chemijournal.com

IJCS 2020; 8(6): 2858-286

(C) 2020 IJCS

Received: 18-09-2020

Accepted: 27-10-2020

Mishra Anupama

College of Community Science,

Central Agriculture University,

Tura, Meghalaya, India

\section{Das Puspita}

College of Community Science,

Central Agriculture University,

Tura, Meghalaya, India

Tiwari Aakanksha

Department of Veterinary

Microbiology, College of

Veterinary \& Animal Sciences, g.

B. Pant University of

Agriculture \& Technology,

Pantnagar, Uttarakhand, India

\section{Kumar Rajesh}

Department of Veterinary

Microbiology, College of

Veterinary \& Animal Sciences, g.

B. Pant University of

Agriculture \& Technology,

Pantnagar, Uttarakhand, India

Mishra L

College of Community Science,

Central Agriculture University,

Tura, Meghalaya, India
Corresponding Author:

Mishra Anupama

College of Community Science,

Central Agricultural University,

Tura, Meghalaya, India

\section{Comparative analysis of total phenolic content and antimicrobial activity of some plants of Garo hills, Meghalaya}

\author{
Mishra Anupama, Das Puspita, Tiwari Aakanksha, Kumar Rajesh and \\ Mishra L
}

\section{DOI: https://doi.org/10.22271/chemi.2020.v8.i6ao.11259}

\begin{abstract}
Eethanolic and aqueous extracts of some plants commonly found in Garo hills of Meghalaya and known for their medicinal value were analysed for total phenolic content and antimicrobial activity. Total content of phenols was quantitatively estimated from extracts of lemon grass, tamarind, Ber, starfruit and Beetle nut. Antimicrobial activity and yield of these plant extracts was also determined. Further, ethanolic extracts have revealed better total phenolic content and antimicrobial activity against test pathogens in comparison to aqueous extracts. Among the plant extracts investigated Beetle nut exhibited highest content of phenols and also best antimicrobial properties. The results show that use of the natural antimicrobial inherent properties occurring in plants extracts is a viable option for the textile finishing industry for functional textile applications. The plant extracts showed high antimicrobial activity which indicates that these extracts may be useful natural remedies for antimicrobial textile finishes for treatment of various types of skin/wound infections and medical textile applications.
\end{abstract}

Keywords: Functional finishes, total phenolic content, antimicrobial activity, plant extracts

\section{Introduction}

Plants are a sustainable source of medicinal products especially in traditional medical practices. Plants contain active substances such as alkaloids, tannins etc., produced during their secondary metabolism which serve as a potential reservoir of medicinal products (Hussein and El-Anssary, 2018) ${ }^{[1]}$. Traditionally, plant extracts have been used for the treatment of pain, inflammation and other musculoskeletal disorders. Medicinal properties of plant extracts may be attributed to secondary metabolites found only in plants belonging to certain species and family, which have been shown to provide protection against pests, animals or UV radiation. Some of the secondary metabolites may be pharmacologically active in humans and useful as medicines. Major secondary metabolites found in plants are phenolics, alkaloids and terpenoids (Tungmunnithum et al., 2018) ${ }^{[2]}$.

Garo hills of Meghalaya are home to several plants, which are being used by local people for medicinal purposes (Sangma and Sahoo, 2017, Sharma et al., 2014) ${ }^{[3,4]}$. Various plant species contain phytochemicals which may be effective for the treatment of certain chronic diseases because they possess antioxidant, antibacterial, antiviral, anti-carcinogenic activities (Zhang et al., 2015, Ramona et al., 2017) ${ }^{[5,6]}$. Despite their significant potential, scarce efforts have been made to explore the medicinal use of plants found in Meghalaya. Therefore, exploration and judicious exploitation of these medicinal plants is required, which will facilitate research in pharmaceutical industry to identify the bioactive components that possess herbal properties. Hence, the present study aimed at determining the amount of total phenolic content as well as antimicrobial activity present in some plants viz., lemon grass, tamarind, Ber, starfruit and Beetle nut commonly found in west Garo hills, Meghalaya. Present investigation is an effort to explore the role of native herbs or plants having medicinal properties as herbal agents in herbal clothing finishes. 


\section{Material and Methods \\ Medicinal Plants}

Medicinal plants selected for this study are commonly found in Garo hills of Meghalaya and are well known for their medicinal properties. Five plant samples were collected from West Garo hills District of Meghalaya (Table-1).

Table 1: Medicinal plants selected for the study

\begin{tabular}{|c|c|c|c|}
\hline Sl. No. & Local name & Scientific name & Part used \\
\hline 1 & Lemon grass & Cymbopogon ctratus & Leaves \\
\hline 2 & Beetle nut & Arecanut catechu & Seeds \\
\hline 3 & Ber & Ziziphus jujube & Leaves \\
\hline 4 & Tamarind & Tamarindus indica & Leaves \\
\hline 5 & Starfruit & Averroha carambola L. & Leaves \\
\hline
\end{tabular}

\section{Preparation of Extracts}

The matured leaves of lemon grass, Ber, Tamarind, Starfruit plants and ripened Beetle nut seeds were collected, cleaned with distilled water and dried at $40^{\circ} \mathrm{C}$ to remove the traces of moisture. Plant material was then crushed using mechanical grinder and sieved to obtain fine powder.

\section{Biochemical extraction}

Plant extracts were prepared using $70 \%$ ethanol (ethanolic extract) and distilled water (aqueous extract) as solvents for analysis of phyto-constituents. Briefly, 2.0 gram of dry powder was mixed separately in $25 \mathrm{ml}$ of each solvent $(70 \%$ ethanol and distilled water) and incubated for 24 hours at room temperature, later centrifuged at $5000 \mathrm{rpm}$ (REMI C-24 Plus refrigerated centrifuge) and the supernatants were separated. Residues were extracted with $25 \mathrm{ml}$ of the respective solvent and the process was repeated. The supernatants obtained were pooled and the extracts obtained were measured and filtered using Whatman filter paper No. $40(125 \mathrm{~mm})$. Extracts were stored at $8{ }^{\circ} \mathrm{C}$ for further analysis within 7 days (Vastrad et al., 2015) ${ }^{[7]}$.

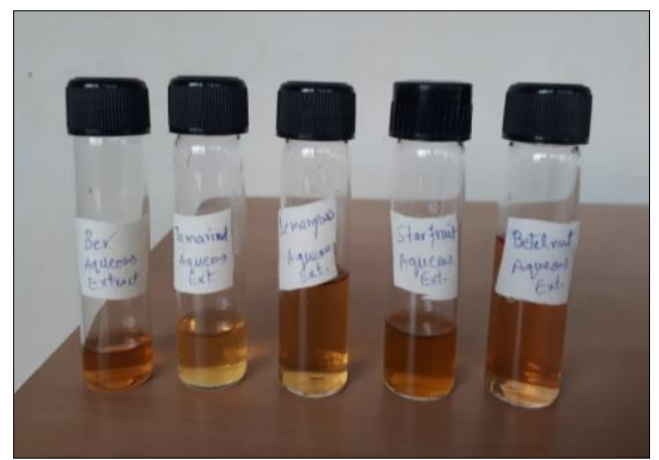

Fig 1: Aqueous herbal extract

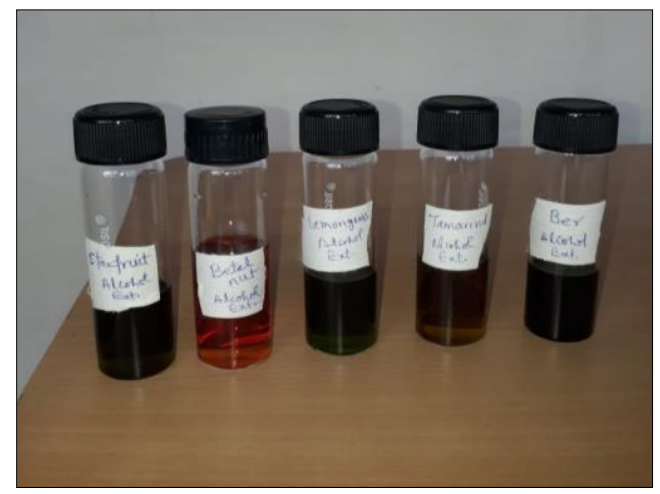

Fig 2: Ethanol herbal extract

\section{Estimation of total phenol content (TPC)}

Total Phenolic Content (TPC) in the extracts was determined by Folin-Ciocalteu assay method (Singleton and Rossi, 1965) with little modification using gallic acid as the reference standard. Briefly, all the extracts were diluted to appropriate volumes and were mixed with $2 \mathrm{ml}$ of $10 \% \mathrm{Na}_{2} \mathrm{CO}_{3}$ solution, incubated at room temperature for $3 \mathrm{~min}$, later $100 \mu \mathrm{l}$ of Folin-Ciocalteu reagent was added to the mixture. The resulting solution was incubated for $90 \mathrm{~min}$ at room temperature under dark; the absorbance was measured at 765 $\mathrm{nm}$ using the UV-Vis Spectrophotometer (BioMate 3S UVVisible Spectrophotometer). The TPC was expressed as Gallic acid equivalent (GAE) in milligrams per gram of dry powder.

\section{Antimicrobial activity of plant extracts}

Bioassay was carried out to assess the antibacterial activity of the plant extracts by Well Diffusion Method. The bacterial species viz., Staphylococcus aureus (ATCC 6538) and Escherichia coli (ATCC 8739) were used for the study. Nutrient agar and nutrient broth media were prepared separately in distilled water and autoclaved at $121{ }^{\circ} \mathrm{C}$ for 15 minutes at a pressure of $15 \mathrm{lbs}$. A loopful of bacterial cultures ( $S$. aureus and E. coli) were mixed separately in the nutrient broth and kept under shaking condition for 24 hours. The nutrient broth containing bacterial inoculum was mixed with sterile nutrient broth and was uniformly spread on sterile Petri plates and allowed to solidify. Later, four wells were created using a cork borer ( $5 \mathrm{~mm}$ diameter). The plant extracts were added to each of the respective 3 wells, one well of being the control sample. Seventy per cent ethanol and distilled water were used as control. Each sample was used in triplicates. The Petri plates were incubated for $18-24 \mathrm{hrs}$ at $37{ }^{\circ} \mathrm{C}$ and observed for bacterial growth. Zone of inhibition of the bacterial growth was measured in millimeters (W.H.O., 1991) [9].

Statistical analysis: Statistical analysis was done as described by Snedecor and Cochran and results were expressed in Mean \pm SD.

\section{Results \& Discussion}

Total yield of the extracts obtained per $50 \mathrm{ml}$ of solvent is given in Table-2. In general, ethanolic extraction gave better yield than distilled water. Maximum yield was recorded for Beetlenut (Arecanut catechu) followed by Lemon grass (Cymbopogon ctratus) for both the solvents.

Table 2: Yield of Plant Extracts

\begin{tabular}{|c|c|c|c|c|c|}
\hline Sl. & Local & & Scientific name & Part & \multicolumn{2}{|c|}{ Yield of extracts $(\mathbf{m l} / 50 m l)$} \\
\cline { 5 - 6 } No. & name & used & $\mathbf{7 0 \%}$ Ethanol & Aqueous \\
\hline 1 & $\begin{array}{c}\text { Lemon } \\
\text { grass }\end{array}$ & $\begin{array}{c}\text { Cymbopogon } \\
\text { citratus }\end{array}$ & Leaves & 25.0 & 21.0 \\
\hline 2. & Beetle nut & $\begin{array}{c}\text { Arecanut } \\
\text { catechu }\end{array}$ & Seed/Nut & 35.6 & 32.6 \\
\hline 3. & Ber & Ziziphus jujube & Leaves & 19.4 & 16.0 \\
\hline 4. & Tamarind & $\begin{array}{c}\text { Tamarindus } \\
\text { indica }\end{array}$ & Leaves & 23.6 & 21.6 \\
\hline 5. & Starfruit & $\begin{array}{c}\text { Averroha } \\
\text { carambola } \text { L. }\end{array}$ & Leaves & 21.4 & 19.6 \\
\hline
\end{tabular}

Bioactive compound i.e. total phenolic content of the plant sources were determined by using the Folin- Ciocalteu reagent in ethanol and aqueous extracts. Plant phenols represent one of the major groups of bioactive compounds acting as primary antioxidants or free radical terminators. 
Significant variation in the total phenolic content of the five plant extracts ranging from 13.81 $\pm 0.36 \mathrm{GAE} \mathrm{mg} / \mathrm{g}$ in Lemon grass aqueous extract to $163.07 \pm 0.16 \mathrm{GAE} \mathrm{mg} / \mathrm{g}$ in Beetle nut ethanolic extract was evident in present study (Table-3).

Table 3: Total Phenolic Content (TPC) of plant extracts

\begin{tabular}{|c|c|c|c|c|c|}
\hline \multirow{2}{*}{$\begin{array}{c}\text { Sl. } \\
\text { No. }\end{array}$} & \multirow{2}{*}{ Local name } & \multirow{2}{*}{ Scientific Name } & \multirow{2}{*}{ Part used } & \multicolumn{2}{|c|}{ Total Phenolic Content GAE(mg/g dried source) } \\
\cline { 5 - 6 } & & & $\mathbf{7 0 \%}$ ethanol & Aqueous \\
\hline 1 & Lemon grass & Cymbopogon ctratus & Leaves & $26.54 \pm 0.60$ & $13.81 \pm 0.36$ \\
\hline 2 & Beetle nut & Arecanut catechu & Seed/Nut & $163.07 \pm 0.16$ & $112.14 \pm 0.13$ \\
\hline 3 & Ber & Ziziphus jujube & Leaves & $43.78 \pm 0.24$ & $22.33 \pm 0.64$ \\
\hline 4 & Tamarind & Tamarindus indica & Leaves & $47.72 \pm 1.60$ & $38.20 \pm 1.24$ \\
\hline 5 & Starfruit & Averroha carambola L. & Leaves & $65.16 \pm 1.53$ & $33.39 \pm 0.38$ \\
\hline
\end{tabular}

The results showed that ethanolic extracts had higher values of TPC than the aqueous extracts. The highest TPC was recorded in Beetlenut (Arecanut catechu) followed by starfruit (Averroha carambola L.,) tamarind (Tamarindus indica), Ber (Ziziphus jujube) and lemon grass (Cymbopogon citratus (Table-3).

Agar gel well diffusion method was used to asses antimicrobial potential of plant extracts against standard test cultures viz. Staphylococcus aureus (gram positive) and E. coli (gram negative) organisms. It was observed that, ethanol extracts of lemon grass showed antibacterial activity against both $S$. aureus $(3.5 \pm 0.42 \mathrm{~mm})$ and $E$. coli $(7.5 \pm 0.62 \mathrm{~mm})$, respectively, whereas distilled water extract of lemon grass showed no inhibition zone against both the organism. Ethanol $(7 \pm 0.82 \mathrm{~mm})$ and distilled water $(6 \pm 0.68 \mathrm{~mm})$ extracts of starfruit showed good antibacterial activity against $S$. aureus but antibacterial activity against $E$. coli was absent in starfruit extracts.

Ethanol extract of Beetlnut was found to exhibit maximum zone of inhibition $(10 \pm 0.71 \mathrm{~mm})$ against Staphylococcus aureus followed by Ber leaves $(9 \pm 0.84 \mathrm{~mm})$, starfruit leaves $(7 \pm 0.82 \mathrm{~mm})$, tamarind $(6 \pm 0.45 \mathrm{~mm})$ and lemon grass (3.5 \pm 0.42$)$. Among the bacterial species, comparatively higher inhibition zone was observed against Gram positive (Staphylococcus aureus) bacteria than Gram negative (Escherichia coli) bacteria.

Table 4: Antimicrobial activity of herbal extracts

\begin{tabular}{|c|c|c|c|c|c|}
\hline \multirow{2}{*}{$\begin{array}{l}\text { Sl. } \\
\text { No }\end{array}$} & \multirow{2}{*}{ Plant extracts } & \multicolumn{3}{|c|}{ Zone of inhibition (mm) } \\
\cline { 3 - 5 } & & \multicolumn{2}{|c|}{ S. aureus } & \multicolumn{2}{c|}{ E. coli } \\
\cline { 3 - 5 } & & Distilled Water & $\mathbf{7 0 \%}$ Ethanol & Distilled water & $\mathbf{7 0 \%}$ ethanol \\
\hline 1. & Lemon grass (Cymbopogon citratus) & Nil & $3.5 \pm 0.42$ & Nil & $7.5 \pm 0.62$ \\
\hline 2. & Beetle nut (Arecanut catechu) & $4 \pm 0.68$ & $10 \pm 0.71$ & $5 \pm 0.82$ & $8.5 \pm 0.82$ \\
\hline 3. & Ber (Ziziphus mauritiana) & $5 \pm 0.32$ & $9 \pm 0.84$ & Nil & $8 \pm 0.54$ \\
\hline 4. & Tamarind (Tamarindus indica) & Nil & $6 \pm 0.45$ & Nil & $7 \pm 0.86$ \\
\hline 5. & Starfruit (Averroha carambola. L.) & $6 \pm 0.68$ & $7 \pm 0.82$ & Nil & Nil \\
\hline
\end{tabular}

The results obtained in the present study suggest that plant extracts derived from lemon grass, tamarind, Ber, starfruit and Beetle nut have moderate to potent antimicrobial activity (Table-4). Polyphenolic compounds have some known properties which include free radical scavenging, antimicrobial, antiallergic activity and anti-inflammatory action etc. (Dugo et al., 2017, Ferreres et al., 2017, shah et al., 2011) [11, 12, 13]. Experimental plant extracts contained appreciable amount of total phenol, which showed that the antimicrobial activity of the plant extracts is influenced by the total phenolic compounds (Elnaggar et al., 2019) ${ }^{[14]}$. These differences in the antioxidant activities may be due to their differences in phenolic contents and compositions and also due to other non-phenolic antioxidants present in the samples (Tungmunnithum et al., 2018, Elnaggar et al., 2019) ${ }^{[2,14] .}$

A study using different concentrations of lemon grass oil showed activity against $S$. aureus, E. Coli and other bacteria (Naik et al., 2010) ${ }^{[15]}$. Our findings are comparable with activity of $5 \%$ essential oil against E. Coli, comparatively smaller inhibition zone against $S$. aureus may be due to difference in sample preparation. Furthermore, smaller zone do not necessarily indicate lesser antimicrobial potential (W. H. O., 1991) ${ }^{[9]}$. Ethanolic and aquous extracts of Arecanut catechu has earlier been shown to possess antibacterial activity against Staphylococcus aureus (Rahman et al., 2014) [16]. However, in our study both extracts exhibited activity against Staphylococcus aureus and E. Coli, this differenc in activity may be attributed to different extraction procedure, type of arecanut and different strains of test organisms. Fruits, seeds and leaves of Ber are believed to possess antimicrobial activity (Pandey and Poonia, 2018) ${ }^{[17]}$. Methanolic extract has been shown to possess antibacterial activity against Staphylococcus aureus (Emad et al., 2016) ${ }^{[18]}$. Flavonoids and polyphenols found in Tamarindus indica leaves have been recorded as antimicrobial agents (Doughari, 2006) ${ }^{[19]}$. Abdallah and Ali (2018) [20] also reported antibacterial activity of tamarind leaves and fruit extract against clinical isolates of E. coli and Shigella sp. Starfruit extracts in various concentrations were shown to inhibit the growth of Staphylococcus aureus and Klebsiella spp. (Chang et al., 2000) [21]. Extracts were also effective against human pathogens like Escherichia coli, Shigella boydii, Salmonella Typhi and Staphylococcus aureus, Candida albicans and Candida krusei (Ma and Wai, 2017, Silva et al., 2020) ${ }^{[23] . ~}$

In conclusion study demonstrates that ber leaves. Lemon grass, Tamarind and starfruit leaves extracts have antimicrobial properties and hence could be exploited as antimicrobial finishes for medical textile and other similar applications for human use.

\section{Acknowledgement}

Financial assistance under All India Coordinated Research Project, ICAR N. Delhi and Central Agricultural University, Imphal to carry out the research is gratefully acknowledged.

\section{References}

1. Rehab A Hussein, Amira A El-Anssary Plants Secondary Metabolites: The Key Drivers of the Pharmacological 
Actions of Medicinal Plants, Herbal Medicine, Philip F. Builders, Intech Open 2018 DOI: 10.5772/intechopen.76139.

2. Tungmunnithum D, Thongboonyou A, Pholboon A, Yangsabai A. Flavonoids and Other Phenolic Compounds from Medicinal Plants for Pharmaceutical and Medical Aspects: An Overview. Medicines (Basel, Switzerland), 2018;5(3):93. https://doi.org/10.3390/medicines5030093

3. Sangma AJT, Sahoo UK. Utilization Pattern of Medicinal Plants by Different Tribes of Garo Hills of Meghalaya, North-East India. Am J Ethnomed 2017;4:1.

4. Sharma, Madhubala, Sharma L, Marak N. Indigenous uses of medicinal plant in North Garo Hills, Meghalaya, NE India. Research Journal of Recent Sciences 2014;3:137-146.

5. Zhang YJ, Gan RY, Li S, Zhou Y, Li AN, Xu DP et al. Antioxidant Phytochemicals for the Prevention and Treatment of Chronic Diseases. Molecules (Basel, Switzerland), 2015;20(12):21138-21156. https://doi.org/10.3390/molecules201219753

6. Ramona Barbieri, Erika Coppo, Anna Marchese, Maria Daglia, Eduardo Sobarzo-Sánchez, Seyed Fazel Nabavi, et al. Phytochemicals for human disease: An update on plant-derived compounds antibacterial activity, Microbiological Research 2017;196:44-68.

7. Vastrad JV, Goudar G, Byadgi SA, Devi RD, Kotur R. Identification of bio-active componentsin leaf extracts of Aloe vera, Ocimum tenuiflorum (Tulasi) and Tinospora cordifolia (Amrutballi). Journal of Medicinal Plants Research 2015;9(28):764-770.

8. Singleton VL, Rossi, Joseph A. Colorimetry of Total Phenolics with Phosphomolybdic-Phosphotungstic Acid Reagents. American Journal of Enology and Viticulture 1965;16(3):144-158.

9. WHO Basic Laboratory Procedures in Clinical Bacteriology 1991, 128. http://helid.digicollection.org/en/d/Jwho01e/8.html.

10. Snedecor GW, Cochran WG. Statistical Methods. New Delhi: Oxford and IBM, Publications 1994, 265.

11. Dugo L, Belluomo MG, Fanali C, Russo M, Cacciola F, MacCarrone $\mathrm{M}$ et al. Effect of cocoa polyphenolic extract on macrophage polarization from proinflammatory M1 to anti-inflammatory M2 state. Oxid. Med. Cell. Longev. 2017, 2017, 6293740

12. Ferreres F, Duangsrisai S, Gomes NGM, Suksungworn R, Pereira DM, Gil-Izquierdo A et al. Anti-inflammatory properties of the stem bark from the herbal drug Vitex peduncularis Wall. ex Schauer and characterization of its polyphenolic profile. Food Chem. Toxicol. 2017;106:816.

13. Shah G, Shri R, Panchal V, Sharma N, Singh B, Mann AS. Scientific basis for the therapeutic use of Cymbopogon citratus, stapf (Lemon grass). Journal of advanced pharmaceutical technology \& research 2011;2(1):3-8. https://doi.org/10.4103/2231-4040.79796

14. Elnaggar, Mahdy, Abdulla, Galal, El-Shourbagy, Gehan, et al. Antimicrobial and Antioxidant Activities of Some Plant Extracts. 2017, 2019.

15. Mohd Irfan Naik, Bashir Ahmad Fomda, Ebenezar Jaykumar, Javid Ahmad Bhat. Antibacterial activity of lemongrass (Cymbopogon citratus) oil against some selected pathogenic bacterias, Asian Pacific Journal of Tropical Medicine 2010;3(7):535-538. https://doi.org/10.1016/S1995-7645(10)60129-0.
16. Arifur Rahman M, Papeya Sultana, Sahidul Islam M, Toslim Mahmud M, Mamun M, Rashid et al. Comparative Antimicrobial Activity of Areca catechu Nut Extracts using Different Extracting Solvents. Bangladesh J Microbiol 2014;31(1, 2):19-23.

17. Pandey, Sonika, Poonia, Amrita. Bioactive compounds, medicinal benefits and value added products of ber fruit: A review 2018, 1460-1466.

18. Abdallah, Emad, Elsharkawy, Eman, Ed-Dra, Abdelaziz. Biological activities of methanolic leaf extract of Ziziphus mauritiana. Bioscience Biotechnology Research Communications. 2016;9:605-614. 10.21786/bbrc/9.4/6.

19. Doughari JH. Antibacterial activity of Tamarindus indica linn. Trop J Pharm. 2006;5(2):597-603.

20. Abdallah MS, Muhammad A. Antibacterial activity of leaves and fruits extract of Tamarindus indica against clinical isolates of Escherichia coli and Shigella at potiskum yobe state, Nigeria. J Anal Pharm Res. 2018;7(5):606-609. DOI: 10.15406/japlr.2018.07.00290

21. Jer-Ming Chang, Shang-Jyh Hwang, Hung-Tien Kuo, Jer-Chia Tsai, Jinn-Yuh Guh, Hung-Chun et al. Fatal outcome after ingestion of star fruit (Averrhoa carambola) in uremic patients, American Journal of Kidney Diseases 2000;35(2):189-193.

22. Maw SS, Wi TT. In vitro Antibacterial and Antioxidant Activities of Star Fruit (Averrhoa carambola). International Journal of Scientific Development and Research 2017;2(2):7-10.

23. Silva KB, Pinheiro CTS, Soares CRM, Souza MA, Matos-Rocha TJ, Fonseca SA et al. Phytochemical characterization, antioxidant potential and antimicrobial activity of Averrhoa carambola L. (Oxalidaceae) against multiresistant pathogens. Brazilian Journal of Biology, Epub 2020. 2020.https://doi.org/10.1590/15196984.220259 